\title{
The use and repair of dental amalgam restorations as practised in South Africa
}

\begin{abstract}
Introduction: Research has confirmed that the replacement of defective restorations is the most commonly performed procedure in general practice. Any defect or sign of secondary caries often led to the complete replacement of a dental restoration. The repair or refurbishment of defective dental amalgam restorations is now considered best practice over replacements.
\end{abstract}

Aims and objectives: To investigate the use and repair of dental amalgam restorations as practised in South Africa.

Methods: Three hundred and twenty-four dentists participated in an electronic cross sectional survey to gather biological data and information on the management of defective amalgam restorations. Analyses included Analysis of Variance (Anova) tests, Chi-square tests, paired $t$ tests and Friedman's test ( $p$-value of $<0.05$ ) (SAS Institute Inc., Cary, NC, USA).

Results: Most dentists ( $\mathrm{n}=62 \%$ ) reported almost never using dental amalgam and an almost equal number $(n=63 \%)$ repaired defective amalgam restorations. Resin composite was the most popular material for the repair $(n=62 \%)$ and replacement $(n=78 \%)$ of defective amalgam restorations. Dentists in this study relied on their clinical experience to derive their repair techniques.

Conclusions: Dental amalgam was no longer a preferred material for the restoration of posterior teeth in South Africa. Resin composite was the most widely used to repair or replace defective amalgam restorations. Dentists practised the repair of defective restorations.

1. Razia Z Adam: $B C h D$, (UWC), $P D D$ (US), MSc Dent (UWC) PhD (UWC). Senior Lecturer, Restorative Dentistry, Faculty of Dentistry, University of the Western Cape, Cape Town.

2. Sue Naidoo: BChD (London), LDS RCS (Eng), MDPH (London), DDPH RCS (Eng), MChD (UWC), PhD(US), PG Dip Int Research Ethics (UCT), DSc (Odont) (UWC). Emeritus Professor, Faculty of Dentistry, University of the Western Cape, Cape Town.

\section{Corresponding author}

Razia Z Adam:

Senior Lecturer, Restorative Dentistry, Faculty of Dentistry, University of the Western Cape, Private Bag X1, Tygerberg, 7505, Cape Town.

E-mail: rzadam@uwc.ac.za

\section{INTRODUCTION}

Dental caries is the most common chronic disease worldwide, affecting nearly all adults ${ }^{1}$ and is the "primary cause of oral pain and tooth loss". ${ }^{2}$ Although there has been a widespread decline in the prevalence of caries in permanent teeth in high-income countries, there are reports of a growing burden of dental caries for adults in low and middle income countries. ${ }^{3}$ This is attributed to increasing urbanisation and changes in dietary habits and living conditions. ${ }^{4}$

In recent years, there has been a trend in caries management away from the operative model towards a more preventive approach - minimum intervention dentistry. ${ }^{4,5}$ This includes strategies that curb the disease process and conserve tooth structure. Traditional curative treatment of dental caries has dominated in countries such the United States of America, ${ }^{6,7}$ although in some regions such as Scandinavia, a more preventative approach has been adopted. ${ }^{2}$ Once sound tooth structure is destroyed through the caries process, there is an ongoing lifelong cycle of repair and maintenance. ${ }^{2,8}$

A wide variety of dental restorative materials exists today. The principal material types for direct restorations include dental amalgam, composites, glass ionomers and resin ionomers. ${ }^{9}$ The use of dental amalgam for the restoration of posterior teeth has decreased because of the need for a more aesthetic material as well as concerns regarding its safety; however, it remains an effective restorative material. ${ }^{4}$

Extensive research has been conducted over the years to investigate the longevity of direct restorations, ${ }^{10-13}$ specifically comparisons between the longevity of dental amalgam and posterior resin composite restorations. Studies conducted by Manhart et al..$^{14}$ and Opdam et $a .^{15}$ found that newer resin composite restorations have an improved longevity. However, a Cochrane Review published in 2014 concluded that the failure rate for composite restorations was twice that of amalgam restorations. ${ }^{16}$ Despite this, increasing concern over aesthetics, the recent Minamata Convention on Mercury ${ }^{17}$ and advances in adhesive dentistry have globally decreased the acceptance of dental amalgam among dentists and patients alike..$^{18}$ 
Hurst $^{16}$ surmised that the failure rate of composite restorations could be four times that of amalgam restorations in a patient with a high caries experience. If dental amalgam were no longer available as a restorative material, populations with high caries rates could therefore be disadvantaged. ${ }^{16}$ The most recent data records dental amalgam being used by $85.8 \%$ of dentists in South Africa. ${ }^{19}$ In these situations, extending the longevity of defective dental amalgam restorations with a repair or refurbishment may be an excellent alternative for increasing the longevity of the restoration and ultimately, the tooth.

This paper reports on the use of dental amalgam as a restorative material in South Africa in light of the Minimata recommendations and the management of defective amalgam restorations.

\section{MATERIALS AND METHODS}

An electronic cross-sectional quantitative survey using Survey Monkey ${ }^{\circledR}$ was distributed to all members of the South African Dental Association (SADA). The study population consisted of 3,076 general practice dentists. Responses were collected for three months and reminders were emailed at 14 day intervals for two months.

The questionnaire consisted of closed and open-ended questions. It elicited information on age, gender, years of experience in practice and highest qualification achieved. The questionnaire also gathered information regarding the practices of the dentists in their management of defective dental amalgam restorations. The questionnaire was adapted from research conducted by Moncada et al. ${ }^{20}$ and Dental PBRN. ${ }^{21,22}$

\section{STATISTICAL ANALYSES}

The Survey Monkey ${ }^{\circledR}$ program collected responses and automatically prepared an Excel spreadsheet. The frequency distributions of all the demographic variables, dental practice profile, continuing professional development, selection of restorative materials and attitudes to repair and replacements of defective amalgam restorations were computed.

Results are presented as frequency distributions and mean scores. For the Analysis of Variance (Anova) tests, Chi-square tests and paired $t$ tests, a $p$-value of $<0.05$ was considered as statistically significant.

In questions for which more than one response could be selected, the Friedman's test was used to determine these differences. The data analyses and re codings were carried out using statistical software SAS (SAS Institute Inc., Cary, NC, USA)

\section{Ethical considerations}

Each participant was asked to complete an online informed consent form. Ethics approval was received from the Senate Research Committee of the University of the Western Cape (Project registration: 11/1/46).

\section{RESULTS}

Initially 388 dentists responded to the online survey. However, six respondents did not agree to participate in the study and an additional seven respondents agreed but did not answer any of the survey questions. The application of the exclusion criteria resulted in a final sample of 324 general dental practitioners currently employed as dentists in the private sector.

\section{Demographics}

More than three quarter $(78 \%)$ of the respondents were younger than 55 years old, with females accounting for just over a third (36\%). More than two thirds (67.7\%) had a $\mathrm{BChD}$ degree as their highest qualification, and just over a quarter (26.7\%) held a postgraduate diploma.

$55 \%$ were self employed in solo practices and $41 \%$ had at least 21 years in private practice. One third were not contracted to medical aid or third party funders.

\section{Choice of dental restorative material}

Most dentists (57\%) reported that they almost always discussed the choice of dental material with the patient and only $11 \%$ almost never did. Amalgam was almost never used as a restorative material by $62 \%$ of respondents while only a small group (7\%) reported almost always using amalgam as a restorative material.

Repair of defective dental amalgam restorations Almost two-thirds (63\%) reported repairing defective dental amalgam restorations in their practice. Of the 37\% who did not repair, 81 respondents provided reasons when asked. Most of the respondents (72\%) felt there was a lack of predictability in the process. This was the major factor in their decision not to repair defective dental amalgam restorations followed by the absence of an established technique (26\%), lack of supporting evidence $(20 \%)$ and the absence of a professional code or fee for the procedure (8.6\%).

\section{AMALGAM REPAIR TECHNIQUE USED}

Table 1 shows the amalgam repair techniques employed by respondents.

\begin{tabular}{|c|c|c|}
\hline Techniques & Frequency & $\%$ \\
\hline Use a bur to create mechanical retention & 189 & 77 \\
\hline $\begin{array}{l}\text { Apply silica coating to the amalgam prior } \\
\text { to bonding }\end{array}$ & 3 & 1.2 \\
\hline $\begin{array}{l}\text { Apply silane coating to the amalgam prior } \\
\text { to bonding }\end{array}$ & 15 & 6 \\
\hline Apply total-etch dentine-bonding system & 120 & 49 \\
\hline Apply self-etch dentine-bonding system & 53 & 21.5 \\
\hline $\begin{array}{l}\text { Apply glass ionomer as a dentine bonding } \\
\text { system }\end{array}$ & 79 & 32.1 \\
\hline Place a pin-retained restoration & 81 & 33 \\
\hline
\end{tabular}

\section{Origin of technique used}

Respondents were asked to indicate where and from whom they had learnt their repair technique. They could select more than one appropriate answer. Using the frequency of individual items chosen, more than two-thirds (68\%) of the participants developed their technique through their own clinical experience, while only $27 \%$ learnt it through attending a continuing professional development course or lecture (Figure 1).

Pairwise comparisons confirmed that undergraduate dental school was chosen significantly more than attending a CPD course or lecture, reading a journal 


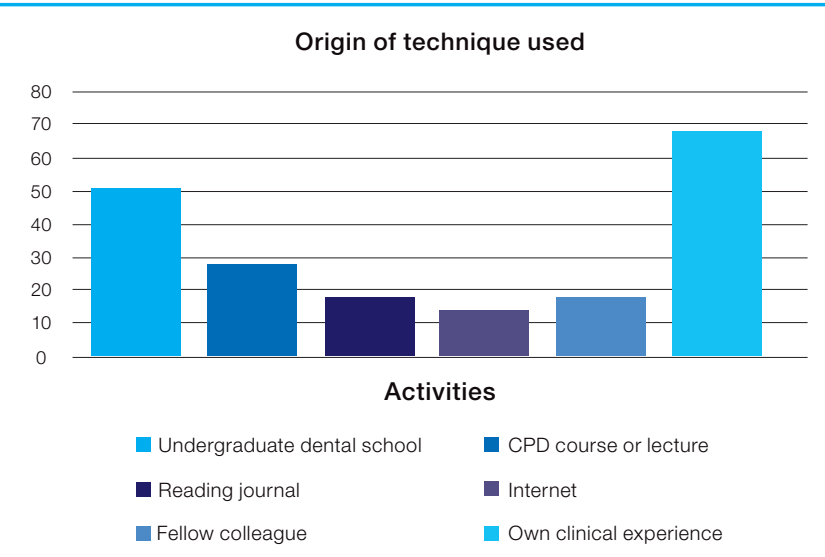

Figure 1: Origin of techniques used (Frequency of individual items chosen)

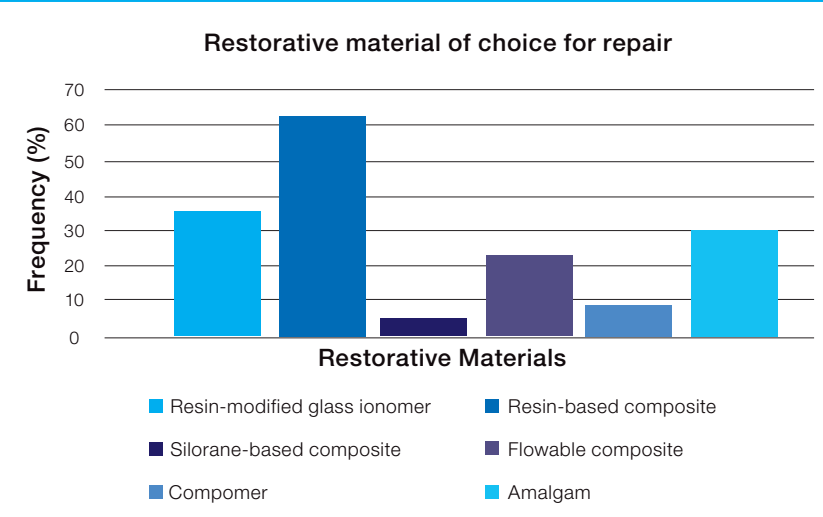

Figure 2: Restorative material of choice for repair (Frequency of individual items chosen)

article, learning from the Internet or learning from a fellow colleague $\left(p<0.0001^{*}\right)$ but was chosen significantly less than the clinical experience of the respondents.

Restorative material of choice for repairing a defective dental amalgam restoration

Resin-based composites were chosen significantly more often than all the other dental restorative materials when repairing a defective dental amalgam restoration (Figure 2). From the pairwise comparisons conducted, it may be seen that resin modified glass ionomer was chosen significantly less than resin-based composite but significantly more than silorane based composite, flowable composite and compomers when a restorative material was selected to repair a defective dental amalgam restoration.

\section{Restorative material of choice for replacing a} defective dental amalgam restoration

Using the frequencies of the most popular single treatment option as in Figure 3, it is evident that resin-based composites were the material of choice when replacing a defective amalgam restoration (78\%). The treatment choice of a crown was also popular, with $58 \%$ of the participants choosing this treatment option. When pairwise comparisons were completed, resin-based composites were chosen significantly more often than all the other possible treatment choices for replacing a defective dental amalgam restoration $\left(p<0.0001^{*}\right)$.

\section{DISCUSSION}

In South Africa in 2014, a total of 5824 dentists were registered with the Health Professions Association of South
Africa (HPCSA), ${ }^{23}$ of whom 3607 were members of the South African Dental Association (SADA). Despite being reminded of their participation fortnightly for two months, there was a low response rate of $10.7 \%$ for the quantitative online survey. A better response would certainly have offered greater confidence in the study. However, this is consistent with other studies that had used the same study population and similar electronic survey methods. ${ }^{24,25}$

The sample included approximately one third female participants. A study of the gender distribution among dental graduates between 2000 and 2005 reported a two fold increase in the number of female graduates. ${ }^{26}$ Previous research conducted in South Africa also noted differences in the working patterns of male and female dentists. A 1997 study found the percentage of male dentists working in private practice was $70 \%$ to $89.7 \% .{ }^{27}$ However, the percentage of female dentists practising more than 35 hours per week has dropped from $86 \%$ to $34 \%$, while the working patterns of male dentists remain unchanged. ${ }^{27}$ Only $19 \%$ of female dentists were the primary breadwinners, indicating that many female dentists were able to work part-time. ${ }^{27}$ In addition, a greater percentage of female than male dentists worked for a salary in government clinics and at academic institutions. ${ }^{27}$ The present study focused on dentists in private practice and if these working patterns have remained unchanged from 1997, and this may have influenced the study population.

\section{Management practices of defective dental} amalgam restorations by South African dentists The findings of the present study were in line with global trends, revealing a decline in amalgam use, with only $7 \%$ of participating dentists using it as a restorative material in South Africa. Despite this, dentists in this study advocated its use due to the excellent lifespan and durability, and a significant number believed it should remain available for clinical use. This is in stark contrast to the $99.7 \%$ of dentists who were using dental amalgam in 1990 and the $85.8 \%$ in $2003 .{ }^{28}$ It should be noted that the 2003 study conducted by Du Preez et al. had only 177 respondents as opposed to 324 in this study. The dramatic decline may be due to the increasing perception that the material is outdated and increasing awareness of patients of the possible harmful effects of dental amalgam.

Approximately $72 \%$ of amalgam restorative treatment is performed to replace existing restorations and the two primary reasons are recurrent caries and faulty margins. ${ }^{21}$ Just a decade ago, dental amalgam was the material of choice in South Africa. ${ }^{28}$ Given that the longevity of

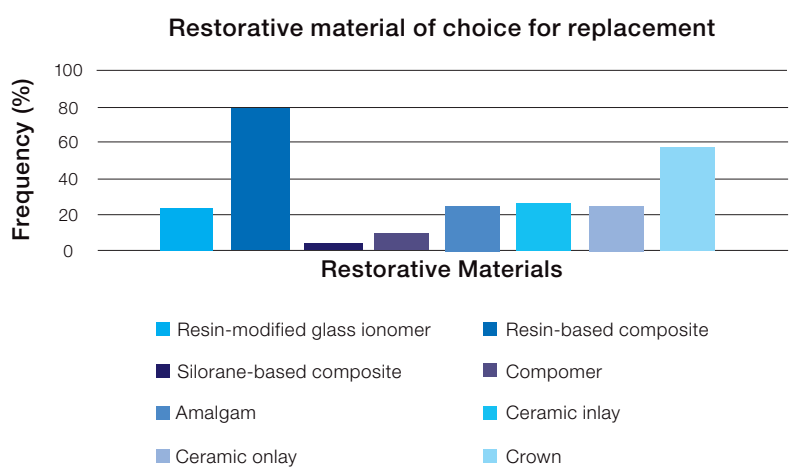

Figure 3 Restorative material of choice for replacement (Frequency of individual items chosen) 
dental amalgam restorations varies between 7 years and 20 years, it is anticipated that South African dentists will be treating more patients with defective dental amalgam restorations in the near future. ${ }^{29}$

Recent studies have confirmed that the repair of defective dental restorations is a clinically viable option to extend the longevity of a restoration without compromising tooth structure or incurring huge costs as in the case of indirect restorations. ${ }^{30,31}$ Data from the self-administered questionnaires revealed that the majority of dentists routinely repair defective dental amalgam restorations.

While no consensus has been reached on a repair technique, recent research has clearly outlined successful and appropriate techniques. ${ }^{32-35}$ The successful repair of a defective restoration is dependent on the formation of a durable bond between the original restoration and the repair material. Macro-mechanical retention is achieved by creating retention features in the restoration or roughening the surface with a coarse diamond bur and micromechanical retention is achieved with the use of etching or the use of air abrasion. ${ }^{35}$ In the present study, a large percentage of the dentists indicated that they would use a bur to create mechanical retention and an almost equal number indicated that they would use a dentine bonding agent to prepare the substrate. ${ }^{33}$ Although phosphoric acid has no effect on the surface characteristics of composites, ceramics and metals, research has shown that it has a favourable effect on retention rates following a repair because of a cleansing action. ${ }^{35}$ Thus, dentists who participated in this study were practising according to current available evidence. However, the most recent recommended protocol for the repair of restorations advocates the use of hydrofluoric acid or the use of air abrasion instead of phosphoric acid. ${ }^{35}$

Once the decision has been taken to repair a restoration, the focus shifts to the selection of a suitable dental restorative material for the repair. In the present study, more than one half of the dentists reported discussing the choice of dental material with patients even though it is possible that most patients would not understand the scientific rationale.

Consistent with the decrease in amalgam usage worldwide and the findings from the National Dental Practice-Based Research Network, ${ }^{36}$ resin composite was the restorative material of choice when repairing a defective dental amalgam restoration. However, similar to the findings of Gordan et al., ${ }^{36}$ a very small number of dentists were confident in the use of amalgam to repair an existing defective dental amalgam restoration. A concern for aesthetics and the perception of a lack of adequate bond strength between dental amalgam and composite could explain these results even though laboratory studies have confirmed favourable bond strengths are attainable. ${ }^{37-39}$

Approximately two thirds of dentists revealed that they had developed their repair technique through their own clinical experience. This behaviour could be explained by two possible opinions. Firstly, clinicians often assume that a treatment is successful based on positive outcomes reported for a number of treated patients. Secondly, the perception that the treatment 'works in my hands' is often seen by general dentists as better evidence that the treatment is clinically viable and acceptable as opposed to data from 'artificial clinical trial settings'. While dentists are bombarded with information from dental company representatives, critical evaluation of the scientific information is often not undertaken. This delays the incorporation of evidence-based dentistry into general dental practice.

This lack of knowledge or competence in the technique potentially means patients are not offered a treatment procedure that has been shown to require less anaesthetic and to promise the conservation of more tooth structure..$^{40}$ Furthermore, the lack of adequate knowledge and skills among South African dentists on how to repair defective restorations may adversely affect health outcomes for an entire population. Until now, the main focus of dentists was to ensure the longevity of the dental restoration. However, in an attempt to break the 'restorative cycle', Opdam proposes that "it is more important to preserve the underlying tooth and the functionality of the dentition as a whole". ${ }^{41}$ Failure of a restoration results in its replacement with a larger restoration, possibly root canal treatment resulting in more complications and eventual extraction of the offending tooth. ${ }^{42}$ Consequences of dental disease- including the loss of teeth - range from pain, impaired eating, interferences in sleeping and speaking, loss of productivity and depressed general health. ${ }^{5}$ This suggests that the indiscriminate replacement of defective restorations raises issues of ethics and quality of care.

While the dentist is responsible for providing appropriate dental care, the responsibility to encourage the implementation of suitable dental care is shared between dental schools and professional organisations. ${ }^{43}$ Dental schools should ensure that their curriculum is based on evidence-based practice. Dentists should be taught how to access sound resources of evidenced-based dentistry and how to incorporate these guidelines into clinical practice. An important part of teaching dental students is to think critically and includes making them aware of conflicting evidence or the absence of evidence. The fact that dentists have adapted their own 'repair technique' may imply that dental schools in South Africa have not yet formally included repair techniques into their curricula, as have the UK, USA and European schools where the repair of direct restorations is taught. ${ }^{44-48}$ Gilmore et al. stated that "the adoption of evidence-based practice by dentists has been slow". ${ }^{49}$ The present study suggests that South African dentists are no different and raises concern regarding the practice of evidence-based dentistry and the competencies of acquiring, maintaining and applying evidence-based knowledge.

\section{CONCLUSIONS}

The present study provides important insights into restorative treatment practices of South African dentists as there is limited data in this field. South African dentists have significantly decreased their use of dental amalgam as a restorative material in favour of resin composites. In addition, dentists in this study were in favour of repairing defective dental amalgam restorations. However, there was much variation in the clinical repair technique used. The lack of knowledge regarding best practice in the management of defective dental amalgam restorations is a cause of concern. It may be helpful for future research 
to interrogate the teaching practices on the repair of dental restorations. Appropriate continuing professional activities should be arranged for practising dentists so that ultimately patients may benefit.

Conflicts of Interest: None declared

This research did not receive any specific grant from funding agencies in the public, commercial, or non-profit sectors.

\section{References}

1. Kassebaum NJ, Bernabé E, Dahiya M, Bhandari B, Murray CJL, Marcenes W. Global burden of untreated caries: a systematic review and meta-regression. J Dent Res. 2015; 94(5): 650-8.

2. Selwitz RH, Ismail Al, Pitts NB. Dental caries. Lancet 2007; 369 (9555):51-9.

3. Abid A et al. Prevalence and severity of oral diseases in the Africa and Middle East Region. Adv Dent Res. 2015; 27(1): 10-7.

4. Petersen P, Baez R Kwan S, Ogawa H. (2009). Future use of materials for dental restoration. World Health Organization.

5. Petersen P. (2003). The World Oral Health Report 2003. Community Dent Oral Epidemiol. 31(Suppl), 3-23.

6. Ismail Al, Hasson H, Sohn W. Dental caries in the second millennium. J Dent Educ. 2001; 65(10): 953-9.

7. Elderton, RJ. Preventive (evidence-based) approach to quality general dental care. Med Princ Pract. 2003; 12(Suppl. 1): 12-21.

8. Elderton RJ, Nuttall NM. Variation among dentists in planning treatment. Br Dent J. 1983; 154(7): 201-6

9. Rekow ED, Bayne SC, Carvalho RM, Steele JG. What constitutes an ideal dental restorative material? Adv Den Res. 2013; 25(1): 18-23.

10. Elderton, RJ. The causes of failure of restorations: A literature review. J Dent. 1976; 4(6): 257-62.

11. Hickel R, Manhart J. Longevity of restorations in posterior teeth and reasons for failure. J Adhes Dent. 2001; 3(1): 45-64.

12. Mitchell, RJ, Koike M, Okabe T. Posterior amalgam restorations: Usage, regulation, and longevity. Dent Clin North Am. 2007; 51(3): 573-89.

13. Moraschini V, Fai CK, Alto RM, Dos Santos, GO. Amalgam and resin composite longevity of posterior restorations: a systematic review and meta-analysis. J Dent. 2015; 43(9): 1043-50.

14. Manhart J, Chen H, Hamm G, Hickel R. Buonocore Memorial Lecture. Review of the clinical survival of direct and indirect restorations in posterior teeth of the permanent dentition. Oper Dent. 2004; 29(5): 481-508.

15. Opdam NJM, van de Sande FH, Bronkhorst E, Cenci MS, Bottenberg P, Pallesen U, van Dijken JW. Longevity of posterior composite restorations: a systematic review and meta-analysis. J Dent Res. 2014; 93(10): 943-9.

16. Hurst D. Amalgam or composite fillings--which material lasts longer? Evid Based Dent . 2014; 15(2): 50-1.

17. Mackey TK, Contreras JT, Liang BA. The Minamata Convention on Mercury: Attempting to address the global controversy of dental amalgam use and mercury waste disposal. Sci Total Environ. 2014; 472: 125-9.

18. Burke FJT, McHugh S, Hall AC, Randall R, Widström E, Forss $H$. Amalgam and composite use in UK general dental practice in 2001. Br Dent J. 2003; 194(11): 613-8; discussion 609.

19. Lombard R, du Preez IC, Oberholzer TG, Gugushe TS. Teaching approaches in South African dental schools: direct restorative procedures. SADJ. 2009; 64(1): 18-20.

20. Moncada G, Fernández EM, Martín J, Arancibia C, Mjör IA, Gordan VV. Increasing the longevity of restorations by minimal intervention: a two-year clinical trial. Oper Dent. 2008; 33(3): 258-64.

21. Gordan VV, Garvan CW, Richman JS, et al. How dentists diagnose and treat defective restorations: evidence from the Dental Practice-based Research Network. Oper Dent 2009;34(6):664-73.

22. Palotie U, Vehkalahti MM. Reasons for replacement of restorations:dentists' perceptions. Acta Odontol. Scand. 2012; 70(6): 485-90.

23. HPCSA. 2014. HPCSA Publications. Retrieved June 14, 2016 , from http://www.hpcsa.co.za/Publications/Statistics.

24. Botha P J, Chikte U, Barrie R, Esterhuizen TM. Self-reported musculoskeletal pain among dentists in South Africa: A 12-month prevalence study. SADJ 2014; 69(5): 208, 210-3.
25. Snyman L, van der Berg-Cloete SE, White JG. The perceptions of South African dentists on strategic management to ensure a viable dental practice. SADJ 2016; 71(1): 12-8.

26. Lalloo R, McMillan W, Gugushe TS, Ligthelm AJ, Evans WG, Moola $\mathrm{MH}$. Gender and race distribution of dental graduates (1985-2004) and first year dental students (2000-2005) in South Africa. SADJ. 2005; 60(5): 206-9.

27. De Wet E, Truter M, Ligthelm AJ. Working patterns of male and female dentists in South Africa. SADJ 1997; 52(1): 15-7.

28. DuPreez IC, Botha C, DeWet, F. Dental materials used by general dental practitioners. SADJ. 2003; 58(4): 149-55.

29. Laske M, Opdam NJM, Bronkhorst EM, Braspenning JCC, Huysmans M. Longevity of direct restorations in Dutch dental practices. Descriptive study out of a Practice Based Research Network. J Dent. 2016; 46: 12-17.

30. Gordan VV et al. Repair or replacement of restorations: a prospective cohort study by dentists in The National Dental Practice-Based Research Network. J Am Dent Assoc. 2015; 146(12): 895-903.

31. Moncada $\mathrm{G}$ et al. Longitudinal results of a 10 -year clinical trial of repair of amalgam restorations. Oper Dent. 2015; 40(1): 34-43.

32. Hickel R, Brüshaver K., Ilie N. Repair of restorations--criteria for decision making and clinical recommendations. Dent Mater. 2013; 29(1): 28-50.

33. Blum I, Lynch CD, Wilson NHF. Factors influencing repair of dental restorations with resin composite. Clin Cosmet Investig Dent. 2014; 6: 81-7.

34. Roeters FJM, Opdam NJM, Loomans BAC. The amalgam-free dental school. J Dent. 2004; 32(5): 371-7.

35. Loomans B, Özcan M. Intraoral repair of direct and indirect restorations: procedures and guidelines. Oper Dent. 2016; 41(S7): S68-S78.

36. Gordan VV, Riley J, Worley DCD, Gilbert GH. Restorative material and other tooth-specific variables associated with the decision to repair or replace defective restorations: findings from The Dental PBRN. J Dent. 2012; 40(5): 397-405.

37. Gordan VV et al. Repair or replacement of defective restorations by dentists in The Dental PBRN. J Am Dent Assoc. 2012; 143(6): 593-601.

38. Özcan M, Schoonbeek G. Bond strength comparison of amalgam repair protocols using resin composite in situations with and without dentin exposure. Oper Dent. 2010; 35(9): 655-62.

39. Cehreli SB, Arhun N, Celik C. Amalgam repair: quantitative evaluation of amalgam-resin and resin-tooth interfaces with different surface treatments. Oper Dent. 2010; 35(3): 337-44.

40. Machado C, Sanchez E, Alapati S, Seghi R, Johnston W. Shear bond strength of the amalgam-resin composite interface. Oper Dent. 2007; 32(4): 341-6.

41. Javidi H, Tickle M, Aggarwal V. Repair vs replacement of failed restorations in general dental practice: factors influencing treatment choices and outcomes. Br Dent J. 2015; 218(1): E2-E2.

42. Opdam N, Frankenberger R, Magne P. From "Direct Versus Indirect" toward an integrated restorative concept in the posterior dentition. Oper Dent. 2016; 41(S7): S27-S34.

43. Fejerskov O, Kidd EAM. (Eds.). (2009). Dental Caries: The Disease and its Clinical Management. John Wiley \& Sons.

44. Setcos JC, Khosravi R, Wilson NHF, Shen C, Yang M, Mjör IA. Repair or replacement of amalgam restorations: Decisions at a USA and a UK dental school. Oper Dent. 2004; 29(4): 392-7.

45. Blum I, Schriever A, Heidemann D, Mjör IA, Wilson NHF. The repair of direct composite restorations: an International Survey of the teaching of operative techniques and materials. Eur $J$ Dent Educ. 2003; 7(1): 41-8.

46. Blum I, Mjör IA, Schriever A. Defective direct composite restorations--replace or repair? A survey of teaching in Scandinavian dental schools. Swed Dent J. 2003; 27(3): 99-104.

47. Gordan VV, Mjör IA, Blum I, Wilson NHF. Teaching students the repair of resin-based composite restorations: a survey of North American dental schools. J Am Dent Assoc. 2003; 134(3): 317-23-29.

48. Hasan M, Khan F. Teaching and practice of repair of dental amalgam restorations in Dental Institutions of Karachi. IJRDPL 2013; (1): 19-26.

49. Gilmore D, Sturmey P, Newton JT. A comparison of the impact of information from a clinician and research-based information on patient treatment choice in Dentistry. J Public Health Dent. 2006; 66(4): 242-7. 